\title{
Geography of Silence - Looking for the True Roma Culture in Polish Geographic Education
}

\author{
Agnieszka Świętek \\ Pedagogical University of Krakow/ Institute of Geography
}

\begin{abstract}
The Roma are the largest but also most marginalized minority group in Europe. In spite of efforts by both public institutions and private organizations to promote inclusivity, marginalization of Roma and other ethnic/minority groups seems to be maintained by geographic education in schools. This study (i) explores the content of Roma in Polish school textbooks at elementary, lower and upper secondary level, (ii) documents the striking absence of the objective narrative, map, photographic materials on the largest minority group in Poland in textbooks, (iii) discusses the reasons behind the paucity of text and illustrative coverage, and (iv) indicates the stereotypes in the depiction of the Roma in the existing textbook content. The lack of Roma content in the Core Curriculum, the official source of material on Poland's history, culture, and geography, is addressed within the context of the "geography of silence" to discusses reasons behind the paucity of text, photo and map coverage. Finally, innovative techniques are presented that can help teachers identify and address these and other silences they may encounter in the curricula.
\end{abstract}

Keywords: ethnic minority, geography of silence, marginalization, Polish Roma, textbooks 